Chronic Obstructive Pulmonary Diseases:

Journal of the COPD Foundation

\author{
Original Research
}

\title{
Pattern and Adherence to Maintenance Medication Use in Medicare Beneficiaries with Chronic Obstructive Pulmonary Disease: 2008-2013
}

Shawn P. E. Nishi, MD ${ }^{1}$ Matthew Maslonka, $\mathrm{MD}^{2}$ Wei Zhang, $\mathrm{MS}^{1}$ Yong-Fang Kuo, $\mathrm{PhD}^{3}$ Gulshan Sharma, MD, $\mathrm{MPH}^{1,2}$

\section{Abstract}

Background: Maintenance medications provide symptomatic relief, improve lung function and reduce the risk of exacerbations in patients with chronic obstructive pulmonary disease (COPD). Despite their proven benefits, limited information exists on maintenance medication use and adherence among users.

Objective: We examined the patterns and factors associated with the receipt of and adherence to maintenance medication in individuals with COPD.

Methods: A retrospective cross-sectional study of $5 \%$ of Medicare beneficiaries enrolled in Parts A, B and D with COPD who received maintenance medication from 2008 to 2013 was conducted. Maintenance medication includes: inhaled corticosteroids (ICSs), long-acting beta2- agonists (LABAs) and long-acting muscarinic antagonists (LAMAs) alone or in combination. We examined the proportion of beneficiaries with COPD who had at least one prescription filled for maintenance medication. Among users of maintenance medications, we also examined adherence, defined as proportion of days covered (PDC) $\geq 80 \%$ over the year from the first maintenance medication prescription fill date.

Results: Overall, maintenance medication (LAMAs, LABAs, ICSs and/or LABA/ICS) use increased from 67.8\% in 2008 to $72.1 \%$ in 2013 . The increase is related to increases in use of LABA/ICS, which rose from $41.1 \%$ in 2008 to $49.6 \%$ in 2013. Factors associated with receipt of maintenance medication include female gender, recent COPD hospitalization (odds ratio [OR] 1.63; 95\% confidence interval [CI] 1.54-1.73), oxygen therapy (OR 1.74 95\% CI, 1.68-1.81), dual eligibility status (OR 1.45; 95\% CI 1.39-1.51), higher education level and evaluation by a pulmonary provider (OR 1.88; 95\% CI 1.81-1.96). The overall adherence among maintenance medication users remained flat. The most important factor associated with adherence was dual eligibility status (OR, 1.67; 95\% CI: 1.59-1.75).

Conclusions: Receipt of maintenance medications increased during the study period and was higher in those with dual eligibility. Overall, adherence to maintenance medications was suboptimal and remained unchanged.

\footnotetext{
Abbreviations: chronic obstructive pulmonary disease, COPD; inhaled corticosteroids, ICSs; long-acting beta2-agonists, LABAs; longacting muscarinic antagonists, LAMAs; proportion of days covered, PDC; odds ratio, OR; confidence interval, CI; phosphodiesterase, PDE4; durable medical equipment, DME; International Classification of Diseases- 9th revision, ICD-9; generalized estimate equation, GEE; metered dose inhaler, MDI

Funding Support: This work was supported by the Agency for Healthcare Research and Quality (R01-HS020642), the Patient-Centered Outcomes Research Institute (1R24HS022134-03), the Clinical and Translational Science Award (1UL1TR001439-01) from the National Center for Advancing Translational Sciences, and the Claude D. Pepper OAIC grant \# P30 AG024832-11. Funders had no role in the preparation, approval or submission of the results.

Date of Acceptance: September 1, 2017

Citation: Nishi SPE, Maslonka M, Zhang W, Kuo Y-F, Sharma G. Pattern and adherence to maintenance medication use in Medicare beneficiaries with chronic obstructive pulmonary disease: 2008-2013. Chronic Obstr Pulm Dis. 2018;5(1):16-26. doi: https://doi. org/10.15326/jcopdf.5.1.2017.0153
} 
1 Division of Pulmonary, Critical Care \& Sleep Medicine, University of Texas Medical Branch, Galveston

2 Department of Internal Medicine, University of Texas Medical Branch, Galveston

3 Sealy Center on Aging, University of Texas Medical Branch, Galveston

\section{Address correspondence to:}

Shawn P.E. Nishi, MD

Division of Pulmonary, Critical Care \& Sleep Medicine

University of Texas Medical Branch

301 University Blvd

Galveston, TX

77555-0561

Email:spnishi@utmb.edu

Telephone: (409)772-2436

\section{Keywords:}

chronic obstructive pulmonary disease; Medicare; inhaled corticosteroids; long-acting beta2-agonists; long-acting muscarinic antagonists; medication adherence

\section{Introduction}

Pharmacological management of patients with chronic obstructive pulmonary disease (COPD) is based on symptoms, disease severity and risk of exacerbation. Long-acting muscarinic antagonists (LAMAs), longacting beta2-agonists (LABAs), phosphodiesterase (PDE-4) inhibitors and the combinations fixed-dose inhaled corticosteroids (ICSs) with a LABA and LABA/ LAMA are approved as maintenance medications to manage patients with moderate to severe COPD. ${ }^{1}$ These medications have been shown to provide symptomatic relief, improve lung function and reduce the risk of exacerbations. ${ }^{1-3}$

Current knowledge of the use of and adherence to maintenance medication comes from randomized controlled trials. ${ }^{4-6}$ In the real-world setting, adherence to clinical practice guidelines is low in patients with COPD. ${ }^{7,8}$ The high burden of comorbidities, complex inhaler regimens, co-existing psychosocial disorders and cost all negatively impact adherence. ${ }^{9-15}$ Moreover, a high proportion of patients prescribed these medications have not undergone spirometry to confirm the diagnosis of COPD. ${ }^{16}$ In general, patients with COPD are undertreated. ${ }^{17}$

We used a $5 \%$ national sample of Medicare beneficiaries with COPD to examine the pattern of maintenance medication use and adherence among maintenance medication users from 2008-2013. We also examined factors associated with the receipt of and adherence to maintenance medication. Our hypothesis was that the overall use of maintenance medication would increase during the study period, but the magnitude of increase would be impacted by the financial burden to the patient.

\section{Methods}

\section{Data Source}

This is a retrospective, cross-sectional study of maintenance medication use in individuals with COPD using a 5\% Medicare beneficiary population, 20082013. This study was approved by the University of Texas Medical Branch Institutional Review Board and informed consent was waived due to the nature of the study. Over $98 \%$ of adults in the United States age $\geq 65$ years are enrolled in Medicare, which includes $>45$ million beneficiaries. The Centers for Medicare and Medicaid Services selects a random sample of $5 \%$ Medicare beneficiaries based on the eighth and ninth digits $(05,20,45,70,95)$ of their health insurance claim number. The resulting standard data is available for research purposes and has been shown to be representative of the entire cohort. ${ }^{18}$

Data from the following files were used for this study: 1) Denominator file (Medicare enrollment information and demographic data); 2) Medicare Provider Analysis and Review file (claims for hospital inpatient and skilled nursing facility stays); 3) Outpatient Standard Analytic File (hospital outpatient services); 4) 100\% Physician/Supplier file (physician and other medical services); 5) Durable Medical Equipment (DME) file; and 6) Part D Drug Event file.

\section{Study Cohort}

A patient met the diagnosis of COPD who had any of the following:

1) At least 2 outpatient or consultation visits (Evaluation and Management codes 99201-99205, 99211-99215) with an encounter diagnosis of COPD at least 30 days apart within a year;

2) One acute care hospitalization with a primary discharge diagnosis of COPD based on the following International Classification of Diseases, 9th revision (ICD-9) codes: 491.x (chronic bronchitis), 492.x (emphysema) or 496 (chronic airway obstruction); or 3) An acute care hospitalization for respiratory failure (ICD-9 codes 518.81, 518.82, 518.84) as the primary discharge diagnosis and COPD listed as the secondary diagnosis. 
A separate denominator file of beneficiaries with COPD was created for each calendar year (20082013). Each file was composed of participants in the year of interest who:

1) Had a diagnosis of COPD;

2) Were age $\geq 66$ years and alive by the end of the year;

3) Had complete Medicare enrollment (Part A, Part B and Part D) and not enrolled in a health maintenance organization in the previous year and current year;

4) Were not a resident of a nursing facility in the previous year and current year; and

5) Were residents in 1 of 9 United States geographic regions.

\section{Variables}

Medicare enrollment files were used to categorize individuals by age (66-74, 75-84, $\geq 85$ years), gender (male, female) and race/ethnicity (white, black, other). Financial burden of medication cost to the patient was determined by dual eligibility status. Dual-eligible beneficiaries refers to individuals qualifying for Medicare Part A and/or Part B who are also eligible for some form of Medicaid benefit. Dual eligibility status was identified by either state buy-in in the enrollment file or low-income subsidy Part D program. The education level at the zip code of residence was obtained from the American Community Survey estimates of the U.S. Census. A comorbidity score (0, 1, $2, \geq 3$ ) was generated using the Elixhauser comorbidity score (excluding COPD) from inpatient and outpatient billing data. ${ }^{19}$

A spirometry examination was identified through Current Procedural Terminology codes (94010, 94014, 94015, 94016, 94060, 94070, 94620). Oxygen therapy use was defined from Healthcare Common Procedure Coding System codes E1390-E1392. Outpatient pulmonary specialist visit was defined as any outpatient visit with a Health Care Financing Administration provider specialty code ("29") during the study year.

\section{Outcome Measures}

Our outcomes of interest were receipt of COPD maintenance medication and maintenance medication adherence in each study year of interest for individuals with COPD. The COPD maintenance medications included LABAs, LAMAs, ICSs, and fixed-dose LABA/ ICS combinations. Medication prescriptions and prescribed dosages were extracted from Part D and DME prescriptions filled. We chose to look at DME files as nebulized medication is covered under DME benefits. For each year, the proportion of days covered (PDC), defined as the proportion of days in a study year that a patient had COPD maintenance medication available from the index prescription filled date, was calculated. The index date was defined as the earliest date a maintenance medication prescription was filled during the study year. For prescriptions extending beyond the end of the year, the days covered were truncated at the end of the year. Beneficiaries were classified as adherent if their PDC $\geq 80 \%$.

\section{Statistical Analysis}

Patient characteristics were summarized from 20082013 using counts and percentages of categorical variables. A generalized estimate equation (GEE) with binomial distribution model analysis was used to assess the trend in outcomes, adjusted for patient characteristics (age, gender, race, dual eligibility status, education level and comorbidity) and health care measures (COPD hospitalization in the previous year, having a spirometry test, oxygen therapy treatment and pulmonary specialist visit). The GEE accounted for the cluster effect of individuals. ${ }^{20} \mathrm{~A}$ priori 2-way interactions on maintenance medication use and adherence was tested between dual eligibility status and education level, and between dual eligibility and study years. All analyses were performed using SAS version 9.4 (SAS Inc., Cary, North Carolina). All reported $p$-values were two-sided with $p<0.05$ considered statistically significant.

\section{Results}

Table 1 presents the baseline characteristics of beneficiaries with COPD by study year. The number of individuals with COPD increased from 13,957 to 18,044 . The majority were female, non-Hispanic white and had $\geq 2$ comorbidities. Over a third of beneficiaries were prescribed home oxygen therapy, were seen by a pulmonary specialist and had spirometry testing.

Table 2 presents receipt of COPD-related medications during the study period. Receipt of any COPD-related medication increased from $85.6 \%$ in 2008 to $87.1 \%$ in 2013. Approximately $72 \%$ of individuals filled some reliever medication, most commonly short-acting beta2-agonists (SABAs) as metered dose inhaler and SABA/SAMA nebulized solutions.

Maintenance medication (LAMAs, LABAs, ICSs and/or LABA/ICS combos) increased from 67.8\% 


\section{Table 1. Baseline Characteristics of Medicare Beneficiaries with COPD and Prescription Medication Benefits: 2008-2013}

\begin{tabular}{|c|c|c|c|c|c|c|}
\hline Characteristics & 2008 & 2009 & 2010 & 2011 & 2012 & 2013 \\
\hline \multirow[t]{2}{*}{ Age (Mean \pm Std) } & $\mathrm{N}=13,957$ & $\mathrm{~N}=15,919$ & $\mathrm{~N}=16,762$ & $\mathrm{~N}=17,144$ & $\mathrm{~N}=17,323$ & $\mathrm{~N}=18,044$ \\
\hline & $75.3 \pm 6.6$ & $76.7 \pm 6.7$ & $76.4 \pm 6.8$ & $76.3 \pm 6.7$ & $76.4 \pm 6.7$ & $76.4 \pm 6.8$ \\
\hline $66-74$ & $7016(50.3)$ & 6845(43.0) & 7493(44.7) & $7747(45.2)$ & $7775(44.9)$ & $8175(45.3)$ \\
\hline $75-84$ & 5531(39.6) & $6841(43.0)$ & $6986(41.7)$ & 7132(41.6) & $7222(41.7)$ & $7360(40.8)$ \\
\hline$\geq 85$ & $1410(10.1)$ & $2233(14.0)$ & 2283(13.6) & $2265(13.2)$ & $2326(13.4)$ & 2509(13.9) \\
\hline \multicolumn{7}{|l|}{ Gender } \\
\hline Male & $5957(42.7)$ & 6063(38.1) & 6542(39.0) & 6784(39.6) & $6943(40.1)$ & $7359(40.8)$ \\
\hline Female & $8000(57.3)$ & 9856(61.9) & $10220(61.0)$ & $10360(60.4)$ & 10380(59.9) & 10685(59.2) \\
\hline \multicolumn{7}{|l|}{ Race } \\
\hline White & 12353(88.5) & $14176(89.1)$ & 14818(88.4) & 15075(87.9) & 15340(88.6) & 16094(89.2) \\
\hline Black & $755(5.4)$ & 925(5.8) & 974(5.8) & $1105(6.5)$ & $1027(5.9)$ & 1064(5.9) \\
\hline Others & $849(6.1)$ & $818(5.1)$ & $970(5.8)$ & 964(5.6) & $956(5.5)$ & $886(4.9)$ \\
\hline \multicolumn{7}{|l|}{ Education Level ${ }^{b}$} \\
\hline 1st quartile & $3452(24.7)$ & $3914(24.6)$ & 4128(24.6) & $4207(24.5)$ & $4277(24.7)$ & 4443(24.6) \\
\hline 2nd quartile & $3385(24.3)$ & $3935(24.7)$ & $4103(24.5)$ & $4260(24.9)$ & $4279(24.7)$ & $4461(24.7)$ \\
\hline 3rd quartile & $3459(24.8)$ & $3875(24.3)$ & $4116(24.6)$ & $4210(24.6)$ & $4256(24.6)$ & $4382(24.3)$ \\
\hline 4th quartile & $3428(24.6)$ & 3932(24.7) & 4129(24.6) & 4204(24.5) & $4239(24.5)$ & $4490(24.9)$ \\
\hline Unknown & $233(1.7)$ & 263(1.7) & $286(1.7)$ & 263(1.5) & $272(1.6)$ & $268(1.5)$ \\
\hline \multicolumn{7}{|l|}{ Dual Eligibility Status $^{c}$} \\
\hline No & $8378(60.0)$ & $9656(60.7)$ & $10049(59.9)$ & $10344(60.3)$ & $10806(62.4)$ & $11617(64.4)$ \\
\hline Yes & $5579(40.0)$ & 6263(39.3) & $6713(40.1)$ & $6800(39.7)$ & $6517(37.6)$ & $6427(35.6)$ \\
\hline Comorbidities Score ${ }^{\mathrm{d}}$ & $2.2 \pm 1.9$ & $2.3 \pm 1.9$ & $2.3 \pm 1.9$ & $2.4 \pm 2.0$ & $2.5 \pm 2.0$ & $2.5 \pm 2.0$ \\
\hline \multicolumn{7}{|l|}{ Comorbidities Group ${ }^{d}$} \\
\hline 0 & 2544(18.2) & 2687(16.9) & $2707(16.2)$ & $2598(15.2)$ & $2490(14.4)$ & $2558(14.2)$ \\
\hline 1 & $3539(25.4)$ & $3891(24.4)$ & $4032(24.1)$ & $4003(23.4)$ & $3937(22.7)$ & $4026(22.3)$ \\
\hline 2 & $3033(21.7)$ & $3415(21.5)$ & $3591(21.4)$ & $3766(22.0)$ & $3785(21.9)$ & $3907(21.7)$ \\
\hline$\geq 3$ & $4841(34.7)$ & $5926(37.2)$ & 6432(38.4) & $6777(39.5)$ & $7111(41.1)$ & $7553(41.9)$ \\
\hline $\begin{array}{l}\text { Hospitalization for Primary COPD } \\
\text { in Previous Year }\end{array}$ & $1222(8.8)$ & $1609(10.1)$ & 1594(9.5) & $1632(9.5)$ & 1702(9.8) & $1589(8.8)$ \\
\hline Oxygen Therapye & $5909(42.3)$ & $6757(42.5)$ & 6854(40.9) & $6989(40.8)$ & $6957(40.2)$ & 7131(39.5) \\
\hline Spirometryf & $5843(41.9)$ & $6743(42.4)$ & $7053(42.1)$ & $7240(42.2)$ & 7496(43.3) & $7958(44.1)$ \\
\hline Pulmonary Specialist Visitg & $6346(45.5)$ & $7568(47.5)$ & $8356(49.9)$ & $8547(49.9)$ & $8811(50.9)$ & 9595(53.2) \\
\hline
\end{tabular}

aA COPD diagnosis is defined as having International Classification of Diseases, ninth revision (ICD-9) codes 491.x [chronic bronchitis], 492.x [emphysema], or 496 [chronic airway obstruction].

${ }^{b}$ The education level at the zip code of residence was obtained from the American Community Survey estimates of the U.S. Census. 'Dual eligibility status: based on whether the patient was eligible for state buy-in coverage provided by the Medicaid program for at least one month or in low-income subsidy part D program during the study year.

dElixhauser comorbidity components: chronic pulmonary disease, congestive heart failure, valvular disease, pulmonary circulation disorders, peripheral vascular disorders, hypertension, paralysis, other neurological disorders, diabetes-uncomplicated,

diabetes-complicated, hypothyroidism, renal failure, liver disease, peptic ulcer disease excluding bleeding, acquired immune deficiency syndrome, lymphoma, metastatic cancer, solid tumor without metastasis, rheumatoid arthritis/collagen vascular diseases, coagulopathy, obesity, weight loss, fluid and electrolyte disorders, blood loss anemia, deficiency anemia, alcohol abuse, drug abuse, psychoses, and depression.

Oxygen therapy was defined from Healthcare Common Procedure Coding System codes E1390-E1392.

fSpirometry was identified through current procedural terminology codes (94010, 94014, 94015, 94016, 94060, 94070, and 94620).

'Pulmonary specialist visit was defined as any outpatient with Health Care Financing Administration Provider Specialty Code "29" 


\section{Table 2. COPD-Specific Medication Usage by Medicare Beneficiaries with COPD: 2008-2013}

\begin{tabular}{|c|c|c|c|c|c|c|}
\hline & 2008 & 2009 & 2010 & 2011 & 2012 & 2013 \\
\hline Any COPD Medication & $\mathrm{N}=13,957$ & $N=15,919$ & $\mathrm{~N}=16,762$ & $N=17,144$ & $\mathrm{~N}=17,323$ & $\mathrm{~N}=18,044$ \\
\hline Use in the Year & $11947(85.6)$ & $13668(85.9)$ & $14555(86.8)$ & $14767(86.1)$ & $14978(86.5)$ & $15715(87.1)$ \\
\hline Maintenance Medication & $9467(67.8)$ & 11086(69.6) & 11850(70.7) & $12198(71.2)$ & 12364(71.4) & $13000(72.1)$ \\
\hline LAMAs & $5320(38.1)$ & $6179(38.8)$ & $6578(39.2)$ & $6782(39.6)$ & $6986(40.3)$ & 7199(39.9) \\
\hline LABAs & $1156(8.3)$ & $1237(7.8)$ & $1284(7.7)$ & $1345(7.9)$ & $1395(8.1)$ & $1447(8.0)$ \\
\hline --LABAs from Part D & $711(5.1)$ & $657(4.1)$ & $518(3.1)$ & $409(2.4)$ & $356(2.1)$ & $345(1.9)$ \\
\hline --LABAs from DME & $486(3.5)$ & $611(3.8)$ & $798(4.8)$ & $967(5.6)$ & $1069(6.2)$ & $1121(6.2)$ \\
\hline ICSs & 2691(19.3) & $2821(17.7)$ & $2849(17.0)$ & $2896(16.9)$ & $2814(16.2)$ & $2837(15.7)$ \\
\hline LABA/ICS & $5736(41.1)$ & $7171(45.1)$ & $7846(46.8)$ & $8103(47.3)$ & $8315(48.0)$ & 8940(49.6) \\
\hline Reliever Medication & $10087(72.3)$ & $11289(70.9)$ & $11918(71.1)$ & 12072(70.4) & $12270(70.8)$ & 12861(71.3) \\
\hline MDI & $7716(55.3)$ & $8886(55.8)$ & $9445(56.4)$ & $9639(56.2)$ & $9815(56.7)$ & $10406(57.7)$ \\
\hline SABAs & $5701(40.9)$ & $6790(42.7)$ & $7430(44.3)$ & $7721(45.0)$ & $8086(46.7)$ & $8908(49.4)$ \\
\hline SAMAs & $573(4.1)$ & $635(4.0)$ & $613(3.7)$ & $538(3.1)$ & $457(2.6)$ & $448(2.5)$ \\
\hline SABA/SAMA & 2693(19.3) & $2785(17.5)$ & 2669(15.9) & $2597(15.2)$ & $2358(13.6)$ & $2241(12.4)$ \\
\hline Nebulized Medication & $5898(42.3)$ & $6257(39.3)$ & 6463(38.6) & $6541(38.2)$ & $6559(37.9)$ & $6740(37.4)$ \\
\hline SABA Alone & $2010(14.4)$ & $2207(13.9)$ & $2332(13.9)$ & $2444(14.3)$ & $2473(14.3)$ & $2615(14.5)$ \\
\hline SAMA Alone & $108(0.8)$ & $157(1.0)$ & $192(1.2)$ & $185(1.1)$ & $183(1.1)$ & $175(1.0)$ \\
\hline SABA/SAMA & $3780(27.1)$ & $3893(24.5)$ & $3939(23.5)$ & $3912(22.8)$ & $3903(22.5)$ & 3950(21.9) \\
\hline
\end{tabular}

LAMAs=long-acting muscarinic agonist; LABAs=long-acting beta2-agonists; DME=durable medical equipment; ICS=inhaled corticosteroids; $\mathrm{MDI}=$ metered dose inhaler; SABA=short-acting beta-agonists; SAMA=short-acting muscarinic agonist

in 2008 to $72.1 \%$ in 2013 . The increase in any maintenance medication during the study period was related to the increase in LABA/ICS combination use, which rose from $41.1 \%$ in 2008 to $49.6 \%$ in 2013 . In contrast, use of an ICS alone decreased from 19.3\% in 2008 to $15.7 \%$ in 2013 . Overall, receipt of LABA prescriptions did not change over the study period. However, handheld device LABA prescriptions decreased, whereas nebulized LABA prescriptions increased, from $3.5 \%$ in 2008 to $6.2 \%$ in 2013 . The receipt of maintenance medications by beneficiaries with COPD seen by a pulmonary specialist was high (77.1\%-79.0\%) but remained unchanged during the study period. In contrast, maintenance medication prescriptions filled by beneficiaries seen by primary care providers increased from $60.1 \%$ in 2008 to $64.6 \%$ in 2013. Across all study years, a higher proportion of women than men received maintenance medication. By gender, maintenance medication prescriptions filled increased from $68.8 \%$ in 2008 to $73.1 \%$ in 2013 in women and from $66.6 \%$ in 2008 to $70.6 \%$ in 2013 in men.

Figure 1 presents maintenance medication use
(A) and adherence (B) by dual eligibility status. During the entire study period, a higher percentage of beneficiaries with dual eligibility status had maintenance medications filled compared to those who had Medicare only, suggesting that co-payment or deductible plays a role in the use of higher cost prescriptions. To examine adherence (B), we performed a subset analysis using beneficiaries who filled a prescription of any maintenance medication during the calendar year. As shown in the figure, individuals with dual eligibility status had a higher mean PDC over the study period, but the mean PDC of either group did not change over the study period.

Table 3 presents the multivariable analyses of odds of receipt of prescription (A) and odds of adherence (B) (defined as PDC $\geq 80 \%$ ) among beneficiaries who filled a maintenance medication prescription. There was a $4 \%$ (odds ratio [OR] 1.04; 95\% confidence interval [CI] 1.03-1.05) increase in the odds of receiving a maintenance medication prescription per year from 2008 to 2013. The odds of receiving a maintenance medication were higher among individuals who were younger, female, with dual eligibility status (OR 1.45; 


\section{Figure 1. COPD Maintenance Medication Use (A) and Adherence (B) by Beneficiaries with COPD by Dual Eligibility Status, 2008-2013}

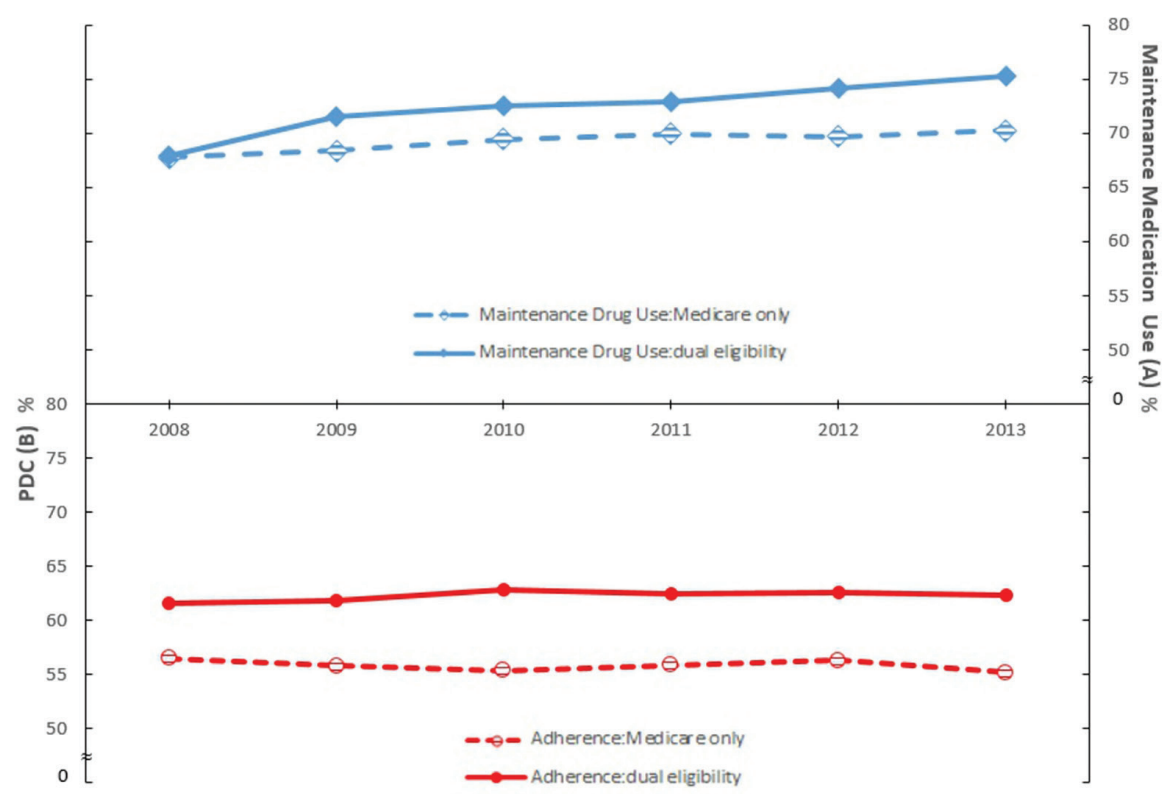

Maintenance medication was identified through LAMAs, LABAs, ICSs and LABA/ICS from Part D file, LABA and ICS from the Durable Medical Equipment file.

Proportion of days covered was defined as the proportion of days in a study year that a patient had COPD maintenance medication available from the index prescription date. For prescriptions extending beyond the end of the year, the days covered were truncated at the end of the year.

LAMAs=long-acting muscarinic agonists; LABAs=long-acting beta2-agonists; ICS $=$ inhaled corticosteroids

95\% CI 1.39-1.51), with more education and those with fewer comorbidities. Beneficiaries who had a COPD hospitalization in the previous year (OR 1.63; 95\% CI 1.54-1.73), had spirometry testing (OR 1.52; 95\% CI 1.47-1.58), received oxygen therapy (OR $1.74 ; 95 \%$ CI $1.68-1.81$ ) or were seen by a pulmonary specialist provider (OR 1.88; 95\% CI 1.81-1.96) also had higher odds of receiving a prescription for a maintenance medication. In a subset analysis using individuals who filled a maintenance medication prescription, overall, there was no increase in the odds of adherence to maintenance medications during the study period. Factors associated with higher odds of adherence among individuals prescribed a maintenance medication include: dual eligibility status (OR 1.67; 95\% CI 1.59-1.75), lower comorbidity burden, prior COPD hospitalization (OR 1.24; 95\% CI
$1.17-1.31$ ), receipt of oxygen therapy (OR, 1.30; 95\% CI, 1.25-1.35) and evaluation by a pulmonary specialist (OR 1.20; 95\% CI 1.14-1.25). We further looked at the interaction of dual eligibility status by education level and dual eligibility status by year and found no significant effect on the interaction between dual eligibility status and education level in either model (maintenance medication prescription or adherence). However, the interaction of dual eligibility status by year had a significant effect on the maintenance medication prescription model. After adjusting for covariates as shown in Table 3 , beneficiaries with dual eligibility status had a greater increase (OR 1.12; 95\% CI 1.09-1.16) in the rate of receiving a maintenance medication prescription per year than those with Medicare only (OR 1.02; 95\% CI 1.01-1.04); But in the adherence model, the interaction effects in both groups (with dual eligibility status and Medicare only) were not significant (OR 1.01 ; $95 \%$ CI $0.98-1.04$ versus OR 0.99; 95\% CI 0.98-1.01).

\section{Discussion}

The results of our study can be summarized as follows:

- maintenance medication use in beneficiaries with COPD is increasing; - the largest increases can be attributed to increased LABA/ICS combination therapy;

- dual eligible (i.e., dual eligibility status) beneficiaries with COPD are more likely to receive a maintenance medication prescription and had a higher rate of increase in receipt of maintenance medications over time.

- Overall adherence to maintenance medication in this population remains suboptimal.

For effective chronic disease management of COPD, appropriate use of recommended prescription medication is crucial. ${ }^{21}$ Studies show low use of and adherence to COPD maintenance medication. 8,10 Patient-related factors associated with risk of poor adherence include unemployment status, less education, low income, living alone and psychosocial comorbidity. ${ }^{13}$ Cross sectional and longitudinal 


\section{Table 3. Multivariable Analyses ${ }^{a}$ of Odds of Maintenance Medication Use (A) and Odds of Adherence (PDC ${ }^{b} \geq 80 \%$ ) to Maintenance Medication (B) Among Beneficiaries with COPD}

\begin{tabular}{|c|c|c|c|c|}
\hline & $\begin{array}{l}\% \text { Maintenance } \\
\text { Medication Use }\end{array}$ & $\begin{array}{c}\text { Odds Ratio } \\
\text { (95\% Cl) of } \\
\text { Maintenance } \\
\text { Medication Use } \\
\text { Among COPD } \\
\text { Beneficiaries }\end{array}$ & $\begin{array}{c}\% \text { Adherence } \\
\text { (PDC } \geq 80 \%)\end{array}$ & $\begin{array}{l}\text { Odds Ratio } \\
(95 \% \mathrm{Cl}) \text { of } \\
\text { Adherence to } \\
\text { Maintenance } \\
\text { Medication } \\
(\text { PDC } \geq 80 \%)\end{array}$ \\
\hline $\begin{array}{l}\text { Change in the Odds per Study Year } \\
\text { Age Group (in years) }\end{array}$ & & $1.04(1.03-1.05)$ & & $1.00(0.99-1.01)$ \\
\hline $66-74$ & 72.2 & Ref & 32.6 & Ref \\
\hline $75-84$ & 70.5 & 0.93(0.90-0.97) & 32.0 & $1.03(0.99-1.07)$ \\
\hline$\geq 85$ & 65.2 & $0.79(0.75-0.84)$ & 31.1 & $1.03(0.97-1.10)$ \\
\hline \multicolumn{5}{|l|}{ Race } \\
\hline White & 70.8 & Ref & 32.2 & Ref \\
\hline Black & 68.0 & $0.92(0.85-0.99)$ & 30.7 & $0.81(0.74-0.89)$ \\
\hline Others & 70.3 & $1.14(1.04-1.24)$ & 33.7 & $0.90(0.82-1.00)$ \\
\hline \multicolumn{5}{|l|}{ Gender } \\
\hline Female & 71.4 & Ref & 32.0 & Ref \\
\hline Male & 69.3 & $0.91(0.88-0.95)$ & 32.5 & $1.07(1.02-1.11)$ \\
\hline \multicolumn{5}{|l|}{ Dual Eligibility Status ${ }^{d}$} \\
\hline No & 69.3 & Ref & 28.4 & Ref \\
\hline Yes & 72.5 & $1.45(1.39-1.51)$ & 37.9 & $1.67(1.59-1.75)$ \\
\hline \multicolumn{5}{|l|}{ Education Levele } \\
\hline 1st Quartile & 67.4 & Ref & 33.0 & Ref \\
\hline 2nd Quartile & 69.5 & $1.12(1.07-1.18)$ & 33.2 & $1.06(1.00-1.13)$ \\
\hline 3rd Quartile & 71.5 & $1.26(1.20-1.33)$ & 31.9 & $1.04(0.98-1.11)$ \\
\hline 4th Quartile & 74.2 & $1.46(1.38-1.55)$ & 30.9 & $1.06(0.99-1.13)$ \\
\hline Unknown & 65.4 & $0.91(0.78-1.06)$ & 29.4 & $0.85(0.71-1.03)$ \\
\hline \multicolumn{5}{|l|}{ Comorbidity Score Groupf } \\
\hline $\mathbf{0}$ & 72.8 & Ref & 35.0 & Ref \\
\hline 1 & 71.3 & $0.90(0.86-0.95)$ & 32.6 & $0.89(0.84-0.94)$ \\
\hline 2 & 70.1 & $0.81(0.77-0.85)$ & 31.4 & $0.81(0.76-0.85)$ \\
\hline$\geq \mathbf{3}$ & 69.5 & $0.69(0.66-0.73)$ & 31.1 & $0.74(0.70-0.78)$ \\
\hline \multicolumn{5}{|c|}{ Any COPD Hospitalization in Previous Year } \\
\hline No & 69.6 & Ref & 31.6 & Ref \\
\hline Yes & 80.0 & $1.63(1.54-1.73)$ & 37.3 & $1.24(1.17-1.31)$ \\
\hline \multicolumn{5}{|l|}{ Spirometry in Current Yearg } \\
\hline No & 65.3 & Ref & 32.3 & Ref \\
\hline Yes & 77.7 & $1.52(1.47-1.58)$ & 32.1 & $0.99(0.95-1.03)$ \\
\hline \multicolumn{5}{|l|}{ Oxygen Therapy in Current Yearh } \\
\hline No & 65.5 & Ref & 29.2 & Ref \\
\hline Yes & 77.9 & $1.74(1.68-1.81)$ & 35.7 & $1.30(1.25-1.35)$ \\
\hline \multicolumn{5}{|c|}{ Pulmonary Specialist Visit in Current Yeari } \\
\hline No & 62.8 & Ref & 31.0 & Ref \\
\hline Yes & 78.5 & $1.88(1.81-1.96)$ & 33.2 & $1.20(1.14-1.25)$ \\
\hline
\end{tabular}

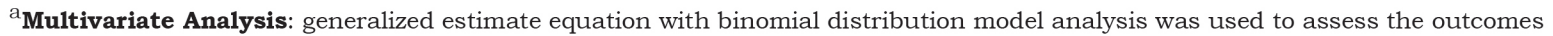
adjusted for patient characteristics (age, gender, race, dual eligibility status, education level and comorbidity) and health care measures (COPD hospitalization in previous year, spirometry treatment, oxygen therapy treatment and pulmonary specialist visit) and accounted for the cluster effect of patient.

${ }^{b}$ PDC: proportion of days covered; COPD: chronic obstructive pulmonary disease; CI: confidence interval.

c A COPD diagnosis is defined as having International Classification of Diseases, ninth revision (ICD-9) codes 491.x [chronic bronchitis], 492.x [emphysema], or 496 [chronic airway obstruction].

${ }^{\mathrm{d}}$ Dual eligibility status: Medicare-Medicaid enrollees; based on whether the patient was eligible for state buy-in coverage provided by the Medicaid program for at least one month or in low-income subsidy part D program during the study year.

${ }^{\mathrm{e}}$ The education level at the zip code of residence was obtained from the American Community Survey (ACS) estimates of the U.S. Census. ${ }^{\mathrm{f}}$ Elixhauser comorbidity components: chronic pulmonary disease, congestive heart failure, valvular disease, pulmonary circulation disorders, peripheral vascular disorders, hypertension, paralysis, other neurological disorders, diabetes-uncomplicated, diabetescomplicated, hypothyroidism, renal failure, liver disease, peptic ulcer disease excluding bleeding, acquired immune deficiency syndrome (AIDS), lymphoma, metastatic cancer, solid tumor without metastasis, rheumatoid arthritis/collagen vascular diseases, coagulopathy, obesity, weight loss, fluid and electrolyte disorders, blood loss anemia, deficiency anemia, alcohol abuse, drug abuse, psychoses, and depression.

gSpirometry was identified through current procedural terminology (CPT) codes (94010, 94014, 94015, 94016, 94060, 94070, and 94620).

hoxygen therapy was defined from Healthcare Common Procedure Coding System (HCPCS) codes E1390-E1392.

${ }^{\mathrm{i}}$ Pulmonary specialist visit was defined as any outpatient visit with HCFA Provider Specialty Code "29"

For personal use only. Permission required for all other uses. 
studies examining the role of depression in adherence to COPD maintenance medication have shown that adherence to COPD maintenance medication falls precipitously within 6 months of use and depression is associated with lower adherence compared to those without depression. ${ }^{10,22,23}$ Other factors related to lower COPD maintenance medication adherence include lack of perceived or actual benefit from the prescribed medication, ${ }^{12,23}$ inability to follow instructions either due to cognitive ${ }^{15}$ or physical inability to use different inhalation devices and out-ofpocket cost of these medications. ${ }^{11,14,24}$

In our study, women were more likely than men to get a prescription for a maintenance medication. However, their adherence to maintenance medication was similar to that of men. This is congruent with prior reports which also showed no association between gender and adherence. ${ }^{8,12}$ One study did show lower adherence in women, but results were confounded by the higher prevalence of depression in women, as the latter is associated with lower adherence. ${ }^{10}$

Our findings of increased maintenance medication use in dual eligible individuals with COPD are worth exploring. Currently, none of the COPD maintenance medications are generic or covered under $\$ 4$ generic prescription programs. However, dual eligible beneficiaries pay no premium and face no deductible under Part D, making these medications affordable under the plan. Beneficiaries who are not dual eligible may not be able to afford these medications. This situation is similar to that of cardiovascular prescriptions in which dual eligible beneficiaries are shown to have higher adherence. ${ }^{25}$

Potential strategies to improve medication adherence will be most successful if undertaken within a multidimensional approach. As shown in our study, the increased adherence over time of dual eligible beneficiaries supports the importance of medication coverage. Health care policy changes should focus on value-based insurance plans and improved prescription drug coverage for Medicare Part D beneficiaries, of whom $17 \%$ enter the coverage gap by October. ${ }^{24}$ Providers should personalize inhaler devices to optimize medication use and delivery, ${ }^{11}$ reduce the complexity of medication regimens whenever possible, 8,14 decrease the number of device types prescribed ${ }^{26}$ and instill inhaler competency for themselves in order to educate patients. ${ }^{27-29}$ Pharmacist-led interventions may include inhaler education and medication synchronization, where all patients' prescriptions are filled on the same day and scheduled closer to the receipt of their income payment. ${ }^{30-32}$ Treatments should ideally include the right medication-device combination for patients rather than a manufacturer proprietary device or insurance formulary determining the availability of a specific medication. Finally, monitoring and feedback about inhaler use through electronic medication delivery devices may assist in medication adherence. ${ }^{32}$

\section{Limitations}

Our study has several limitations. The analysis is limited to fee-for-service Medicare beneficiaries who had Medicare Parts A, B and D and is nongeneralizable to managed Medicare or commercial insurance populations with COPD. Actual spirometry values and dyspnea scores cannot be assessed using administrative claims to verify a diagnosis or severity of COPD. However, we used surrogates for disease severity such as oxygen use, prior COPD hospitalization and clinic assessment by a pulmonary physician. The medication "use" is based on a prescription filled. This does not account for medications prescribed and never filled or medications used appropriately. Dual eligibility status is based on Medicaid coverage for at least 1 month during the entire year and may not be a true representation of the patient's poverty status. Nonetheless, this measure is shown to be a good surrogate of the socioeconomic status of Medicare beneficiaries. $^{33}$

In summary, maintenance medication use in fee-forservice Medicare beneficiaries increased during the study period and is higher in dual eligible beneficiaries. However, the overall adherence to maintenance medications is suboptimal and remains unchanged.

\section{Acknowledgements}

The authors thank Sarah Toombs Smith, PhD, ELS for help with preparation of the manuscript. Dr. Toombs Smith received no compensation for her work beyond her salary as a University of Texas Medical Branch employee. Authorship/Contributorship:

SPEN: Made substantial contributions to 1) conception and design, interpretation of data; 2) drafting the article or revising it critically for important intellectual content; and 3) final approval of the version to be published; guarantor of the paper; $\mathrm{MM}: 1$ ) interpretation of data; 2) drafting the article or revising it critically for 
important intellectual content; and 3) final approval of the version to be published; WZ: 1) acquisition of data, 2) analysis and interpretation of data, 3) final approval of the version to be published; Y-FK: 1) substantial contributions to conception and design, 2) analysis and interpretation of data, 3) final approval of the version to be published; GS: 1) substantial contributions to conception and design, acquisition of data, or analysis and interpretation of data; 2) drafting the article or revising it critically for important intellectual content; and 3) final approval of the version to be published.

\section{Declaration of Interest}

GS serves on the advisory board of Theravance Biopharma, Mylan and Sunovion pharmaceutical companies. The other co-authors have no financial conflicts of interest to disclose. 


\section{References}

1. Global Initiative for Chronic Obstructive Lung Disease (GOLD). Global Strategy for the Diagnosis, Management and Prevention of COPD 2017. GOLD website. http://goldcopd.org. Published January 2017. Accessed October 2017.

2. Kew KM, Dias S, Cates CJ. Long-acting inhaled therapy (betaagonists, anticholinergics and steroids) for COPD: a network meta-analysis. Cochrane Database Syst Rev. 2014(3):CD010844. doi: https://doi.org/10.1002/14651858.CD010844.pub2

3. Chong J, Leung B, Poole P. Phosphodiesterase 4 inhibitors for chronic obstructive pulmonary disease. Cochrane Database Syst Rev. 2013(11):CD002309. doi: https://doi.org/10.1002/14651858.CD002309.pub4 .

4. Vestbo J, Anderson JA, Calverley PM, et al. Adherence to inhaled therapy, mortality and hospital admission in COPD. Thorax. 2009;64(11):939-943.

doi: https://doi.org/ 10.1136/thx.2009.113662 .

5. Rand CS, Nides M, Cowles MK, Wise RA, Connett J. Long-term metered-dose inhaler adherence in a clinical trial. The Lung Health Study Research Group. Am J Respir Crit Care Med. 1995; 152(2):580-588.

doi: https://doi.org/10.1164/ajrccm.152.2.7633711.

6. Tashkin DP, Celli B, Senn S, et al. A 4-year trial of tiotropium in chronic obstructive pulmonary disease. $N$ Engl $\mathrm{J}$ Med. 2008;359(15):1543-1554.

doi: https://doi.org/10.1056/NEJMoa0805800.

7. Nilsson JL, Haupt D, Krigsman K, Moen J. Asthma/COPD drugs reflecting disease prevalence, patient adherence and persistence. Expert Rev Respir Med. 2009;3(1):93-101. doi: https://doi.org/10.1586/17476348.3.1.93

8. Krigsman K, Moen J, Nilsson JL, Ring L. Refill adherence by the elderly for asthma/chronic obstructive pulmonary disease drugs dispensed over a 10-year period. J Clin Pharm Ther. 2007;32(6):603-611.

doi: https://doi.org/10.1111/j.1365-2710.2007.00866.x

9. Osterberg L, Blaschke T. Adherence to medication. $N$ Engl $J$ Med. 2005;353(5):487-497.

doi: https://doi.org/10.1056/NEJMra050100

10. Albrecht JS, Park Y, Hur P, et al. Adherence to maintenance medications among older adults with chronic obstructive pulmonary disease: The role of depression. Ann Am Thorac Soc. 2016. doi: https://doi.org/10.1513/AnnalsATS.201602-136OC

11. Koehorst-ter HK, Movig K, van der Valk P, van der Palen J, Brusse-Keizer $M$. The influence of type of inhalation device on adherence of COPD patients to inhaled medication. Expert Opin Drug Deliv. 2016;13(4):469-475.

doi: https://doi.org/10.1517/17425247.2016.1130695.
12. Krauskopf K, Federmn AD, Kale MS, et al. Chronic obstructive pulmonary disease illness and medication beliefs are associated with medication adherence. COPD. 2015;12(2):151-164. doi: https://doi.org/10.3109/15412555.2014.922067.

13. Tottenborg SS, Lange P, Johnsen SP, Nielsen H, Ingebrigtsen TS, Thomsen RW. Socioeconomic inequalities in adherence to inhaled maintenance medications and clinical prognosis of COPD. Respir Med. 2016;119:160-167.

doi: https://doi.org/10.1016/j.rmed.2016.09.007

14. Toy EL, Beaulieu NU, McHale JM, et al. Treatment of COPD: Relationships between daily dosing frequency, adherence, resource use, and costs. Respir Med. 2011;105(3):435-441. doi: https://doi.org/10.1016/j.rmed.2010.09.006

15. Turan O, Turan PA, Mirici A. Parameters affecting inhalation therapy adherence in elderly patients with chronic obstructive lung disease and asthma. Geriatr Gerontol Int. 2016; 17(6).9991005. doi: https://doi.org/10.1111/ggi.12823

16. Nishi SP, Wang Y, Kuo YF, Goodwin JS, Sharma G. Spirometry use among older adults with chronic obstructive pulmonary disease: 1999-2008. Ann Am Thorac Soc. 2013;10(6):565-573. doi: https://doi.org/10.1513/AnnalsATS.201302-037OC

17. Make B, Dutro MP, Paulose-Ram R, Marton JP, Mapel DW. Undertreatment of COPD: a retrospective analysis of US managed care and Medicare patients. Int J Chron Obstruct Pulmon Dis. 2012;7:1-9. doi: https://doi.org/10.2147/COPD.S27032

18. Sustic A, Krstulovic B, Eskinja N, Zelic M, Ledic D, Turina D. Surgical tracheostomy versus percutaneous dilational tracheostomy in patients with anterior cervical spine fixation: preliminary report. Spine. 2002;27(17):1942-1945. doi: https://doi.org/10.1097/00007632-200209010-00026

19. Elixhauser A, Steiner C, Harris DR, Coffey RM. Comorbidity measures for use with administrative data. Medical Care. 1998;36(1):8-27.

doi: https://doi.org/10.1097/00005650-199801000-00004

20. Zou G. A modified poisson regression approach to prospective studies with binary data. Am J Epidemiol. 2004;159(7):702-706. doi: https://doi.org/10.1093/aje/kwh090

21. Simoni-Wastila L, Wei YJ, Qian J, et al. Association of chronic obstructive pulmonary disease maintenance medication adherence with all-cause hospitalization and spending in a Medicare population. Am $J$ Geriatr Pharmacother. 2012;10(3):201-210.

doi: https://doi.org/10.1016/j.amjopharm.2012.04.002.

22. Qian J, Simoni-Wastila L, Rattinger GB, et al. Association between depression and maintenance medication adherence among Medicare beneficiaries with chronic obstructive pulmonary disease. Int $J$ Geriatr Psychiatry. 2014;29(1):49-57. doi: https://doi.org/10.1002/gps.3968. 
23. Khdour MR, Hawwa AF, Kidney JC, Smyth BM, McElnay JC. Potential risk factors for medication non-adherence in patients with chronic obstructive pulmonary disease (COPD). Eur J Clin Pharmacol. 2012;68(10):1365-1373.

doi: https://doi.org/10.1007/s00228-012-1279-5.

24. Yu YF, Hearld LR, Qu H, Ray MN, Kilgore ML. Association of Part D coverage gap with COPD medication adherence. Am J Manag Care. 2016;22(8):e275-282.

25. Doll JA, Hellkamp AS, Goyal A, Sutton NR, Peterson ED, Wang TY. Treatment, outcomes, and adherence to medication regimens among dual medicare-medicaid-eligible adults with myocardial infarction. JAMA Cardiol. 2016;1(7):787-794. doi: https://doi.org 10.1001/jamacardio.2016.2724.

26. Restrepo RD, Alvarez MT, Wittnebel LD, et al. Medication adherence issues in patients treated for COPD. Int $J$ Chron Obstruct Pulmon Dis. 2008;3(3):371-384.

doi: https://doi.org/10.2147/COPD.S3036

27. Darba J, Ramirez G, Sicras-Mainar A, Francoli-Martinez P, Torvinen S, Sanchez-de la Rosa R. The importance of inhaler devices: an incorrect inhaler technique leads to suboptimal medication compliance in patients with COPD. Value Health. 2015;18(7):A362. doi: https://doi.org/10.1016/j.jval.2015.09.703.

28. Goodwin R, Heraghty J. Do healthcare professionals understand asthma devices? Arch Dis Child Educ Pract Ed. 2015;100(6):302305. doi: https://doi.org/10.1136/archdischild-2015-308779.

29. Fink JB, Rubin BK. Problems with inhaler use: a call for improved clinician and patient education. Respir Care. 2005;50(10):13601374.

30. Davis E, Marra C, Gamble JM, et al. Effectiveness of a pharmacist-driven intervention in COPD (EPIC): study protocol for a randomized controlled trial. Trials. 2016;17(1):502. doi: https://doi.org/10.1186/s13063-016-1623-7.

31. van der Molen T, van Boven JF, Maguire T, Goyal P, Altman P. Optimizing identification and management of COPD patients - reviewing the role of the community pharmacist. $\mathrm{Br} J$ Clin Pharmacol. 2016. doi: https://doi.org/10.1111/bcp.13087.

32. Pilcher J, Holliday M, Ebmeier S, McKinstry S, Messaoudi F, Weatherall $M$, et al. Validation of a metered dose inhaler electronic monitoring device: implications for asthma clinical trial use. BMJ Open Respir Res. 2016;3(1):e000128. doi: https://doi.org/10.1136/bmjresp-2016-000128 .

33. Bernheim SM, Parzynski CS, Horwitz L, et al. Accounting for patients' socioeconomic status does not change hospital readmission rates. Health Aff (Millwood). 2016;35(8):1461-1470. doi: https://doi.org/10.1377/hlthaff.2015.0394 . 